Research article Open Access

\title{
Cigarette smoking associates with body weight and muscle mass of patients with rheumatoid arthritis: a cross-sectional, observational study
}

\author{
Antonios Stavropoulos-Kalinoglou1,2,3, Giorgos S Metsios ${ }^{1,2,3}$, Vasileios F Panoulas ${ }^{3}$, \\ Karen MJ Douglas ${ }^{3}$, Alan M Nevill1,2, Athanasios Z Jamurtas4,5, Marina Kita ${ }^{3}$, \\ Yiannis Koutedakis ${ }^{1,4,5}$ and George D Kitas ${ }^{2,3,6}$
}

\begin{abstract}
1School of Sport, Performing Arts \& Leisure, Wolverhampton University, Gorway Road, Walsall, WS1 3BD, West Midlands, UK ${ }^{2}$ Research Institute in Healthcare Science, University of Wolverhampton, Wulfruna Street, Wolverhampton, WV1 1LY, West Midlands, UK 3Department of Rheumatology, Dudley Group of Hospitals NHS Trust, Russell's Hall Hospital, Pensnett Road, Dudley, DY1 2HQ, West Midlands, UK ${ }^{4}$ Department of Sport and Exercise Science, University of Thessaly, Trikala-Karyes Road, Trikala, 42100, Greece

5 Institute of Human Performance \& Rehabilitation, Trikala-Karyes Road, Trikala, 42100, Greece

${ }^{6}$ ARC Epidemiology Unit, University of Manchester, Oxford Road, Manchester, M13 9PT, UK

Corresponding author: Antonios Stavropoulos-Kalinoglou, as@wlv.ac.uk
\end{abstract}

Received: 20 Nov 2007 Revisions requested: 7 Jan 2008 Revisions received: 7 Mar 2008 Accepted: 20 May 2008 Published: 20 May 2008

Arthritis Research \& Therapy 2008, 10:R59 (doi:10.1186/ar2429)

This article is online at: http://arthritis-research.com/content/10/3/R59

(C) 2008 Stavropoulos-Kalinoglou et al.; licensee BioMed Central Ltd.

This is an open access article distributed under the terms of the Creative Commons Attribution License (http://creativecommons.org/licenses/by/2.0), which permits unrestricted use, distribution, and reproduction in any medium, provided the original work is properly cited.

\begin{abstract}
Introduction Rheumatoid arthritis (RA) is associated with altered metabolism leading to muscle wasting. In the general population, cigarette smoking is known to affect body composition by reducing fat and inhibiting muscle synthesis. Even though smoking has been implicated in the pathophysiology and progression of RA, its possible effects on body composition of such patients have not been studied. This cross-sectional study aimed to identify potential associations of smoking with body weight and composition of RA patients.
\end{abstract}

Methods A total of 392 patients (290 females) with RA were assessed for body mass index (BMI), body fat (BF), fat-free mass (FFM), and waist circumference. Erythrocyte sedimentation rate, C-reactive protein, Disease Activity Score28, and Health Assessment Questionnaire score were used to assess disease activity and severity. Smoking habit (current smoker, ex-smoker, or never-smoker) and intensity (pack-years) were also noted.

Results Current smokers had a significantly lower BMI compared with ex-smokers (mean difference: male -2.6, 95\% confidence interval [Cl]: -3.5 to -1.7 ; female: $-2.6,95 \% \mathrm{Cl}:-4.8$ to -0.5 ) and never-smokers (mean difference: male $-1.8,95 \%$ $\mathrm{Cl}:-3$ to -0.6 ; female: $-1.4,95 \% \mathrm{Cl}:-2.4$ to -0.4 ). Similarly, the BF of current smokers was lower compared with that of exsmokers (mean difference: male: $-4.3,95 \% \mathrm{Cl}-7.5$ to -1.2 ; female: $-3.4,95 \% \mathrm{Cl}-6.4$ to -0.4 ) and never-smokers (mean difference: male: $-3.3,95 \% \mathrm{Cl}:-6.3$ to -0.4 ; female: $-2.1,95 \%$ $\mathrm{Cl}:-4$ to -0.2$)$. FFM did not differ between groups. Finally, current smokers had a significantly smaller waist circumference compared with ex-smokers only (mean difference: male: -6.2 , 95\% Cl: -10.4 to -1.9 ; female: $-7.8,95 \% \mathrm{Cl}:-13.5$ to -2.1 ). Following adjustments for age, disease duration, and $\mathrm{HAQ}$ score, smoking remained a significant predictor for BMI $(P<$ $0.001)$, BF $(P<0.05)$, and waist circumference $(P<0.05)$. Pack-years were inversely correlated with BF $(r=-0.46 ; P<$ $0.001)$, and heavy smokers exhibited a significantly lower FFM $(P<0.05)$ compared with all other participants.

Conclusion Within the limitations of a cross-sectional study, it appears that cigarette smoking associates with reduced $\mathrm{BMI}$ and BF in patients with RA and heavy smoking associates with lower muscle mass. Smoking cessation appears to associate with increased BMI, BF, and waist circumference in these patients. These results should be confirmed in prospective studies. Given the numerous adverse effects of smoking on general health and RA, patients should be actively advised against it. However, smoking cessation regimes in RA may need to include more general lifestyle counselling, particularly about weight control. 


\section{Introduction}

Rheumatoid arthritis (RA), the commonest inflammatory arthritis, is associated with altered metabolism [1]. Compared with healthy controls, RA patients exhibit elevated resting energy expenditure (REE) and enhanced muscle catabolism [2]. Such changes may lead to rheumatoid cachexia (that is, involuntary loss of fat-free mass [FFM] with a proportional increase of body fat $[\mathrm{BF}]$ ) in the presence of stable body weight $[3,4]$. Body composition changes, particularly BF increase, may remain largely undetected by traditional assessments such as the body mass index (BMI) [5]. Increased BF, together with reduced levels of physical activity due to joint inflammation and damage $[3,6]$, is associated with several comorbidities, including cardiovascular disease $[7,8]$ as well as increased mortality [3].

Cigarette smoking is an important risk factor for several diseases [9]. It is also known to decrease body weight in healthy individuals by reducing appetite and increasing REE [10]. In contrast, smoking cessation may associate with significant weight increase, which constitutes a major deterrent to smoking control [11].

We have recently demonstrated that smoking further increases REE in RA [12] and this could potentially augment rheumatoid cachexia in these patients. Given the RA-related alterations in body composition and the comorbidity associated with them, the examination of potential contributors to muscle wasting, such as smoking, is important. The aim of this cross-sectional study was to detect potential associations between smoking and body weight, body composition, and rheumatoid cachexia in RA patients.

\section{Materials and methods Participants}

Consecutive patients attending routine rheumatology clinics at the Dudley Group of Hospitals NHS Trust, UK, were invited to participate. All applicable institutional and governmental regulations concerning the ethical use of human volunteers were followed during this research. The study had local research ethics committee and research and development directorate approvals, and all volunteers provided informed consent. A total of 400 volunteers (108 males and 292 females) with RA (1987 revised American College of Rheumatology criteria [13]) were assessed. Of them, 8 (6 males) were excluded from the analyses due to missing data for body composition. Data from the remaining 392 (median age: 63.1 [55.5 to 69.6] years; median disease duration: 10 [4 to 18] years) were analysed.

\section{Assessments}

All volunteers were subjected to the same data collection procedures overseen by the same trained investigators. Standing height was measured to the nearest $0.5 \mathrm{~cm}$ on a Seca 214 Road Rod portable stadiometer (Seca gmbh \& co. kg., Hamburg, Germany). Body weight and composition (that is, BF and FFM) were assessed using a Tanita BC- 418 MA Segmental Body Composition Analyzer (Tanita Corporation, Tokyo, Japan). After initial manual entry of their demographic details, participants stood barefooted on the analyzer and held the handgrips provided until the apparatus printed the results. BMI was calculated on the basis of measured height and weight in kilograms per square metre. Waist circumference was also measured. Contemporary disease activity was assessed by the erythrocyte sedimentation rate (ESR), C-reactive protein (CRP), and the Disease Activity Score-28 (DAS28) [14]. The Anglicised version of the 40-item Stanford Health Assessment Questionnaire (HAQ) [15] was used to measure physical dysfunction as a proxy of disease severity. Patients' self-reported smoking status and intensity (that is, pack-years) were noted.

\section{Data management and analyses}

Data were analysed using the Statistical Package for Social Sciences version 15.0 (SPSS Inc., Chicago, IL, USA). A preliminary evaluation of the variables using a Kolmogorov-Smirnov test of normality revealed that none of them required transformation to reach normality. Mean \pm standard deviation was calculated for all variables. Differences in BMI, BF, and FFM between smoking groups are presented as mean differences with $95 \%$ confidence intervals (Cls).

According to their smoking status, patients were grouped into never-smokers, current smokers, and ex-smokers. Analysis of variance (ANOVA) assessed differences in demographic characteristics, BMI, and body composition between groups for each gender. Analysis of covariance (ANCOVA) was employed to determine whether the differences observed were attributed to smoking status or other confounding factors (for example, gender, age, and disease characteristics).

In the current smoker and ex-smoker groups, further associations between pack-years with BMl and body composition were examined. Thereafter, patients in these groups were divided into quartiles according to pack-years. ANOVA was employed to assess differences in the measured variables between these subgroups. ANCOVA was used to correct for any confounding factors.

Thereafter, patients were grouped according to (a) RA-specific BMI [5] and (b) gender-specific BF [16] thresholds into underweight, normal weight, overweight, and obese. Subsequently, they were grouped based on gender-specific cut-off 
points for waist circumference [17] into low or high risk and for FFM into low or normal FFM groups [18]. Chi-square analyses were employed to assess differences between smoking groups in the prevalence of overweight, obesity, high risk, and low FFM. For all tests, the level of significance was set at a $P$ value of less than 0.05 .

\section{Results}

Table 1 illustrates means \pm standard deviations and the ANOVA results for all studied parameters. Current smokers had a significantly lower BMI than ex-smokers (mean difference: male $-2.6,95 \% \mathrm{Cl}:-3.5$ to -1.7 ; female: $-2.6,95 \% \mathrm{Cl}$ 4.8 to -0.5 ) and never-smokers (mean difference: male -1.8 , 95\% Cl: -3 to -0.6 ; female: $-1.4,95 \% \mathrm{Cl}:-2.4$ to -0.4$)$. Current smokers also had a significantly lower BF compared with exsmokers (mean difference: male: $-4.3,95 \% \mathrm{Cl}-7.5$ to -1.2 ; female: $-3.4,95 \% \mathrm{Cl}:-6.4$ to -0.4 ) and never-smokers (mean difference: male: $-3.3,95 \% \mathrm{Cl}:-6.3$ to -0.4 ; female: $-2.1,95 \%$ $\mathrm{Cl}:-4$ to -0.2 ). FFM did not differ between these groups (mean difference: current smokers versus ex-smokers, male: -4.6 , $95 \% \mathrm{Cl}:-10.7$ to 1.6 ; female: $-1.2 ; 95 \% \mathrm{Cl}:-3.8$ to 1.4 ; current smokers versus never-smokers, male: $-2.7,95 \% \mathrm{Cl}:-9.2$ to 3.9 ; female: $0.1,95 \% \mathrm{Cl}:-2.4$ to 2.4 ). Current smokers had a significantly smaller waist circumference than ex-smokers (mean difference: male: $-6.2,95 \% \mathrm{Cl}:-10.4$ to -1.9 ; female: $7.8,95 \% \mathrm{Cl}:-13.5$ to -2.1 ) but not never-smokers (mean difference: male: $-2.9,95 \% \mathrm{Cl}:-10.6$ to 4.9 ; female: $-3.9,95 \%$ $\mathrm{Cl}:-9.2$ to 1.5$)$. Also, ex-smokers had a larger waist circumference than never-smokers but the difference was significant for males only (mean difference: male: $3.3,95 \% \mathrm{Cl}: 0.4$ to 6.3 ; female: $3.9,95 \% \mathrm{Cl}:-0.4$ to 8.1 ).

In ANCOVA with gender and smoking as factors and age, DAS28, HAQ score, and disease duration as covariates, smoking was a significant and independent predictor for $\mathrm{BMI}$ $\left(\mathrm{F}_{2,387}=8 ; P<0.001\right), \mathrm{BF}\left(\mathrm{F}_{2,387}=4.4 ; P<0.05\right)$, and waist circumference $\left(\mathrm{F}_{2,387}=7.9 ; P<0.001\right)$. Smoking also emerged as a significant predictor of FFM $\left(\mathrm{F}_{2,387}=5.1 ; P<\right.$ $0.05)$, but inclusion of $\mathrm{BMI}$ as a covariate eliminated the effect of smoking on FFM $(P>0.05)$.

There was a significant negative correlation between packyears and BF $(r=-0.46 ; P<0.001)$ in the current smoker and the ex-smoker groups. This remained significant after adjustment for gender, age, DAS28, HAQ score, and disease duration $\left(\mathrm{F}_{1,389}=4.8 ; P<0.05\right)$. Following pack-year grouping into quartiles (pack-group), ANOVA did not reveal any differences for BMI or body composition among the current and ex-smoker pack-groups. However, an ANCOVA model with gender and pack-group as factors and age and weight as covariates (following stepwise elimination of ESR, CRP, DAS28, HAQ score, and disease duration) revealed a significant effect of pack-group on FFM $\left(\mathrm{F}_{3,217}=2.7 ; P<0.05\right)$, with heavy smokers exhibiting the lowest values. Mean $(95 \% \mathrm{Cl})$ values of this variable in the pack-year subgroups appear in Figure 1.

Following BMI and BF grouping, chi-square analyses showed significant differences $(P<0.05)$ in the prevalence of over-

Table 1

Measured variables of participants classified as current smokers (CS), ex-smokers (XS), and never-smokers (NS)

\begin{tabular}{|c|c|c|c|c|c|c|}
\hline \multirow{2}{*}{$\begin{array}{l}\text { Gender } \\
\text { Smoking status }\end{array}$} & \multicolumn{3}{|c|}{ Male $(n=102)$} & \multicolumn{3}{|c|}{ Female $(n=290)$} \\
\hline & CS & XS & NS & CS & XS & NS \\
\hline Number & 20 & 50 & 32 & 49 & 97 & 144 \\
\hline Age, years & $58.8 \pm 8.1^{a}$ & $65.2 \pm 9.9 b$ & $58.8 \pm 15$ & $57.4 \pm 13.3^{a}$ & $64.1 \pm 11.2^{\mathrm{b}}$ & $60.7 \pm 11.8$ \\
\hline Height, cm & $171.3 \pm 7.1$ & $174.3 \pm 6.9$ & $172.7 \pm 7.7$ & $160.9 \pm 6.9$ & $160.8 \pm 6.8$ & $159.5 \pm 6.8$ \\
\hline Weight, kg & $76 \pm 12.9^{b, c}$ & $85.8 \pm 13.6$ & $84.1 \pm 14.8$ & $67.5 \pm 14.2^{\mathrm{a}}$ & $74.8 \pm 15.2$ & $69.9 \pm 13.6$ \\
\hline Body mass index, $\mathrm{kg} / \mathrm{m}^{2}$ & $25.8 \pm 3.3^{b, c}$ & $28.4 \pm 3.8$ & $27.6 \pm 4.6$ & $26.1 \pm 5.5^{a, b}$ & $28.6 \pm 5.4$ & $27.5 \pm 5$ \\
\hline Body fat, percentage & $24.5 \pm 6.4^{c, d}$ & $28.8 \pm 6.8$ & $27.8 \pm 5.6$ & $35.9 \pm 7^{a}, b$ & $39.2 \pm 6.5$ & $38.1 \pm 6.7$ \\
\hline Fat-free mass, $\mathrm{kg}$ & $57.2 \pm 9.4$ & $61.7 \pm 7.7$ & $59.8 \pm 10.3$ & $42.5 \pm 4.8$ & $43.7 \pm 6.1$ & $42.5 \pm 6.1$ \\
\hline Waist circumference, $\mathrm{cm}$ & $100 \pm 7.9^{c}$ & $106.2 \pm 10.8^{b}$ & $102.9 \pm 9.3$ & $90.8 \pm 12.8^{a}$ & $98.6 \pm 13$ & $94.7 \pm 12.7$ \\
\hline $\mathrm{ESR}, \mathrm{mm} / \mathrm{hour}$ & $26.5 \pm 20.5$ & $22.8 \pm 21.3$ & $20.7 \pm 19.7$ & $30.5 \pm 26$ & $34.3 \pm 32.7^{b}$ & $25.5 \pm 19.8$ \\
\hline C-reactive protein, $\mathrm{mg} / \mathrm{L}$ & $13.3 \pm 9.4$ & $16.1 \pm 20.4$ & $16 \pm 24.3$ & $21.9 \pm 23.2^{b}$ & $21.4 \pm 32.7 \mathrm{~b}$ & $11.9 \pm 12.5$ \\
\hline DAS28 & $4 \pm 0.9$ & $4.1 \pm 1.5$ & $3.9 \pm 1.6$ & $4.5 \pm 1.5$ & $4.3 \pm 1.5$ & $4.1 \pm 1.2$ \\
\hline HAQ score & $0.9 \pm 0.8$ & $1.4 \pm 1$ & $1.1 \pm 0.9$ & $1.5 \pm 0.9$ & $1.5 \pm 0.9$ & $1.5 \pm 0.9$ \\
\hline Disease duration, years & $8.6 \pm 7.8$ & $11.9 \pm 10.6$ & $14.6 \pm 12.7$ & $11.4 \pm 9.8$ & $13.5 \pm 10.8$ & $13.5 \pm 11.1$ \\
\hline
\end{tabular}

Values are presented as mean \pm standard deviation. aSignificant difference compared with XS $(P<0.05)$. bSignificant difference compared with NS $(P<0.05)$. cSignificant difference compared with XS $(P<0.001)$. dSignificant difference compared with NS $(P<0.001)$. DAS28, Disease Activity Score-28; ESR, erythrocyte sedimentation rate; HAQ, Health Assessment Questionnaire. 
Figure 1

(a) Males

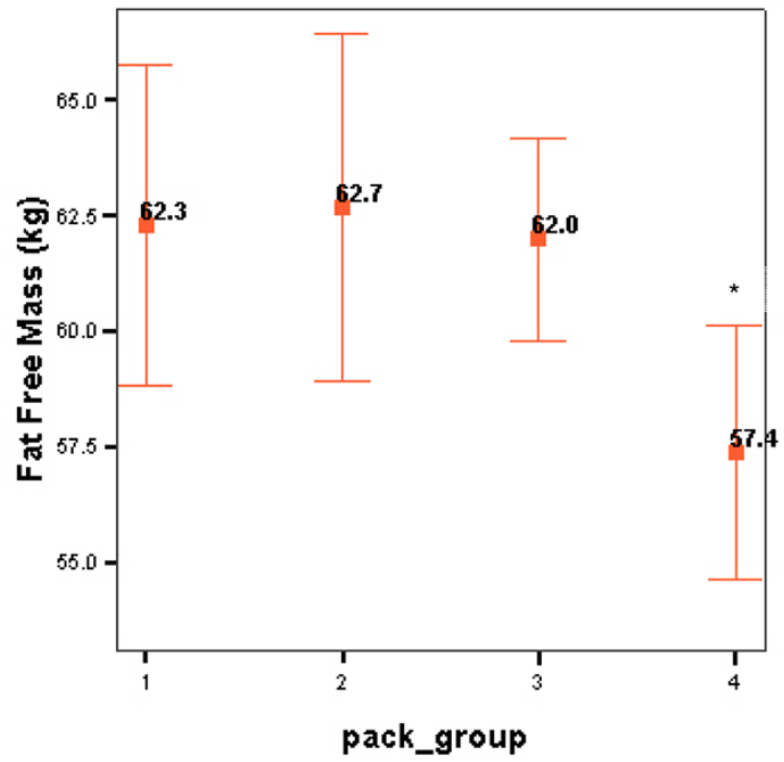

(b) Females

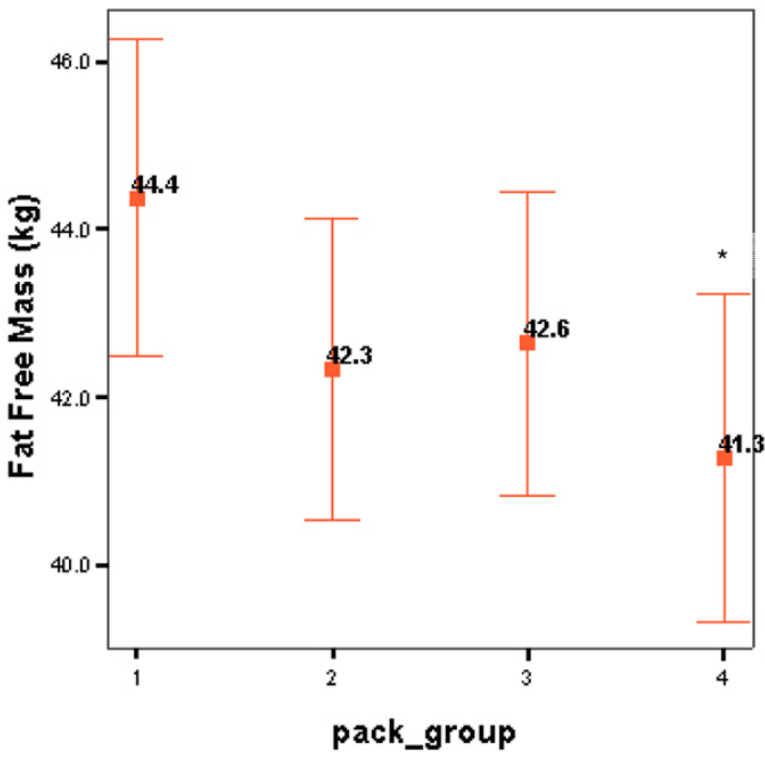

Fat-free mass for males (a) and females (b) according to pack-year grouping. Data are presented as means with $95 \%$ confidence intervals. Packyear groups: 1, 1 to 9 pack-years; 2, 10 to 19 pack-years; 3, 20 to 34 pack-years; 4, greater than 35 pack-years. Asterisk indicates significant difference compared with group $1(P<0.05)$.

weight and obesity among smoking groups, with obesity being more prevalent in ex-smokers $(50 \%)$ followed by never-smokers (39\%) and current smokers (30\%). Similarly, ex-smokers had a significantly $(P<0.05)$ higher prevalence of increased waist circumference (69\%) compared with never-smokers $(60 \%)$ and current smokers (49\%). However, FFM did not differ between groups $(P>0.05)$ (Figure 2$)$.

\section{Discussion}

To our knowledge, this is the first study to identify significant associations between smoking, body weight, and body composition of RA patients: current smokers had a significantly lower BMI and BF compared with never-smokers. Both BMI and BF were significantly increased in ex-smokers, whereas very heavy smoking appeared to associate with reduced FFM. The study has several potential limitations. These are all crosssectional associations, and although they can serve for hypothesis generation, they do not provide definitive evidence for causality or directionality: longitudinal studies are required for this. In addition, body composition was assessed by bioelectrical impedance. This method has been validated [19-23] and is thought to be suitable for body composition studies in diverse populations [22-25], correlates well with the 'gold standards' of dual-energy x-ray absorptiometry and hydrostatic weighing [23], and is widely used in RA research $[5,12,24,26,27]$, but it has not actually been specifically validated in the RA population. Finally, although self-report of smoking, especially smoking history, is generally reliable, both under- and over-reporting can occur [28]. This is unlikely to have influenced the primary findings of this study (that is, the differences between current, ex-, and non-smokers), while any misreporting in pack-years may have been smoothed by the large number of participants. It is difficult to assess any other selection bias: the prevalence of current, ex-, and non-smokers among the participants of this study was similar to that reported for local general population subjects of similar age [29], although it was different from an RA cohort established more than 10 years ago [30].

Our observations for BMl are consistent with those in the general population. Both male and female smokers tend to have decreased BMl compared with their non-smoking counterparts [10,31]. In contrast, significant BMl increases have been noted after smoking cessation [11]. Smokers have increased levels of leptin [32], which regulates food intake and fat deposition [33], and reduced hypothalamic neuropeptide $Y$ [34], which regulates appetite [35]. Smoking-induced increases in the levels of epinephrine, norepinephrine, and thyroid hormones lead to increased energy expenditure at rest $[36,37]$ and during light physical activity [38-40]. However, these effects are short-lived: after smoking cessation, leptin decreases to levels below those expected for non-smokers of similar weight [32] and resting energy expenditure (REE) returns to normal [41].

In patients with RA, smoking has been shown to elevate REE [12]; however, no data are available on other potential contributors to smoking-related weight loss or smoking cessation- 
Figure 2

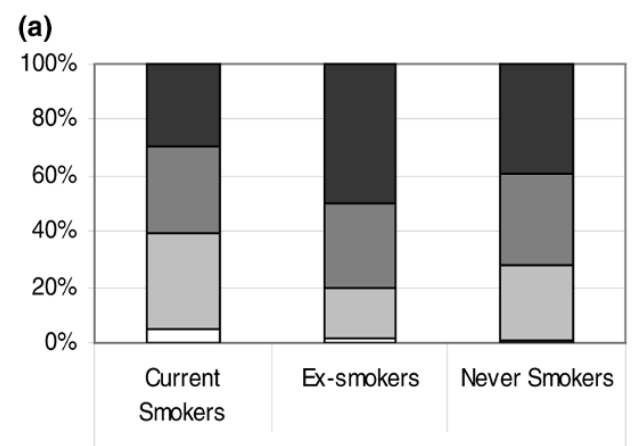

RA-specific Body Mass Index Categories (b)

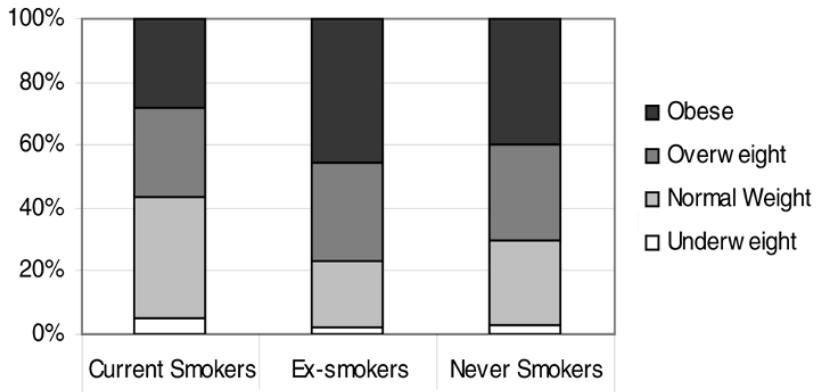

Body Fat Categories (c)

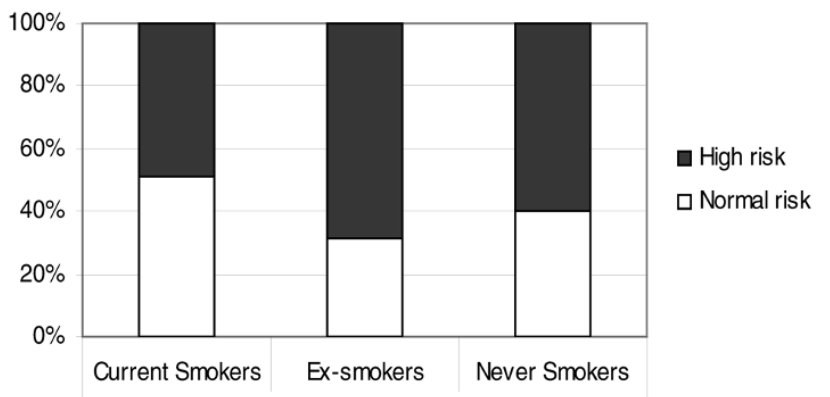

Waist Circumference
- Obese

口 Overw eight

口 Normal Weight

$\square$ Underw eight (d)

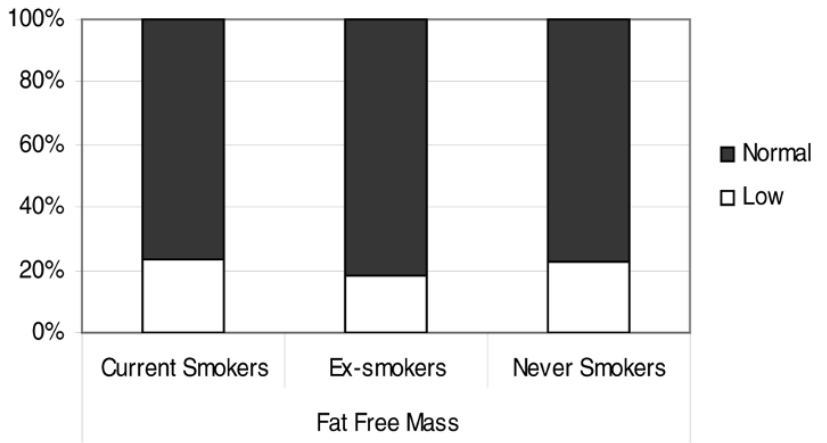

Prevalence of overweight and obesity, increased waist circumference, and low fat-free mass in smoking groups. (a) Prevalence of overweight and obesity based on rheumatoid arthritis (RA)-specific body mass index for current, ex-, and never-smokers. (b) Prevalence of overweight and obesity based on body fat for current, ex-, and never-smokers. (c) Prevalence of high risk based on waist circumference for current, ex-, and never-smokers. (d) Prevalence of low fat-free mass for current, ex-, and never-smokers. Chi-square analyses identified significant defences among smoking groups for prevalence of (a) overweight and obesity based on body mass index $(P<0.05)$, (b) overweight and obesity based on body fat $(P<0.05)$, and (c) increased waist circumference $(P<0.05)$. Prevalence of low fat-free mass did not differ between groups $(P>0.05)$.

related weight gain for this population. Although we did not assess energy intake and expenditure or related regulators (such as leptin), it is likely that the mechanisms behind the reduced body weight of current smokers and the increased body weight of ex-smokers with RA are similar to those described for the general population.

Interestingly, the lower BMl of current smokers in the present study seems to be due to decreased BF rather than FFM. A possible mechanism by which smoking may affect fat metabolism is through a reduction in neuropeptide $\mathrm{Y}$. This molecule not only stimulates food intake, but also promotes white fat lipid storage and decreases brown fat thermogenesis [35], so its inhibition through smoking would be expected to have the opposite effects. Additionally, smoking results in decreased adipose tissue lipoprotein lipase activity [42], which diverts fat storage away from adipose tissue and toward utilization by muscle [43], possibly leading to the decreased BF of smokers $[42,44]$. In the present study, the inverse association between smoking and BF appeared to be dose-dependent: increasing pack-years associated with reducing BF levels. Smoking cessation is thought to result in a reversal of the mechanisms described above, leading to increases in BF [42] and, most importantly, abdominal fat [45]. Indeed, among these RA patients, ex-smokers seemed to be the most 'unhealthy' group in terms of body weight and composition as they exhibited the highest BMI, BF, and waist circumference values.

In predominantly healthy people who are from the general population and who do not have wasting muscle disease, smoking of any intensity has been implicated in muscle wasting [10] by impairing the process of muscle protein synthesis [46]. In contrast, in the present study, only very heavy smoking appeared to associate with a reduction in FFM. It is possible that the effect of smoking on muscle is of less significance than the muscle loss associated with RA itself, as part of rheumatoid cachexia. This hypothesis is supported by the finding that increased duration of smoking (that is, pack-years) associated with lower FFM in both current and ex-smokers, which suggests the existence of a threshold below which smoking does 
not induce further muscle loss in RA patients. A longitudinal study of the impact of smoking intensity (and cessation) on the body composition of patients with RA may throw more light on the mechanistic basis of these observations.

Overall, this study suggests that, in RA, smoking associates with reduced body mass and fatness without inducing further muscle loss, except in very heavy smokers; in contrast, smoking cessation associates with increased body mass and fatness. This should not be interpreted as favouring what is a very unhealthy habit. Smoking cessation, even if it occurs in midlife, reduces most of the later risk of death from tobacco [47]. However, smoking cessation is known to result in body weight increase, and this may affect some people's decision to stop smoking $[11,44,45]$. Therefore, any smoking cessation regime should be underpinned by more generalised lifestyle counselling, including advice on exercise and weight management. This is emphasized by the fact that, based on recently described RA-specific BMI [5], BF [16], and waist circumference thresholds [48], ex-smokers have the highest prevalence of obesity - both total and abdominal. FFM did not differ between groups and the prevalence of low FFM was comparable to that expected in age- and gender-matched healthy individuals [18].

\section{Conclusion}

Within the limitations of this study, it is concluded that RA smokers have a lower BMI and BF than RA non-smokers, while heavy smokers also have a reduced FFM. A history of smoking cessation appears to associate with increases in BMI, BF, and waist circumference. Nevertheless, given the numerous adverse effects of smoking on health, smokers with RA should be actively advised against it, but smoking cessation programs should include wider lifestyle counselling for weight control, also focusing on increased physical activity and a healthy diet.

\section{Competing interests}

The authors declare that they have no competing interests.

\section{Authors' contributions}

AS-K participated in patient recruitment, data collection and analysis, and the drafting of the manuscript. GSM participated in patient recruitment and in data collection and analysis. VFP and KMJD participated in patient recruitment, rheumatological clinical assessments, and application of diagnostic/classification criteria. AMN provided expert statistical advice and supervision and participated in the review of the manuscript. AZJ participated in the inception and development of protocol and in the review of the manuscript and served as PhD program supervisor. MK provided advice on protocol development and body composition assessments and participated in the review of the manuscript. YK participated in the inception and development of protocol and served as $\mathrm{PhD}$ program supervisor. GDK participated in the inception and development of protocol, patient recruitment, clinical assessments, and analytical approach, provided supervision in the drafting of the manuscript, and served as PhD program supervisor and study guarantor.

\section{Acknowledgements}

This study was funded by a Dudley Group of Hospitals research and development directorate cardiovascular program grant and a Wolverhampton University equipment grant. The Department of Rheumatology, Dudley Group of Hospitals, has an infrastructure support grant from the Arthritis Research Campaign (number 17682).

\section{References}

1. Roubenoff R, Roubenoff RA, Cannon JG, Kehayias JJ, Zhuang $H$ Dawson-Hughes B, Dinarello CA, Rosenberg IH: Rheumatoid cachexia: cytokine-driven hypermetabolism accompanying reduced body cell mass in chronic inflammation. J Clin Invest 1994, 93:2379-2386.

2. Rall LC, Roubenoff R: Rheumatoid cachexia: metabolic abnormalities, mechanisms and interventions. Rheumatology (Oxford) 2004, 43:1219-1223.

3. Walsmith J, Roubenoff R: Cachexia in rheumatoid arthritis. Int $J$ Cardio/ 2002, 85:89-99.

4. Metsios GS, Stavropoulos-Kalinoglou A, Koutedakis Y, Kitas GD: Rheumatoid cachexia: causes, significance and possible interventions. Hospital Chronicles 2006, 1:20-26.

5. Stavropoulos-Kalinoglou A, Metsios GS, Koutedakis Y, Nevill AM, Douglas KM, Jamurtas A, van Zanten JJ, Labib M, Kitas GD: Redefining overweight and obesity in rheumatoid arthritis patients. Ann Rheum Dis 2007, 66:1316-1321.

6. Metsios GS, Stavropoulos-Kalinoglou A, Veldhuijzen van Zanten JJ, Treharne GJ, Panoulas VF, Douglas KM, Koutedakis Y, Kitas GD: Rheumatoid arthritis, cardiovascular disease and physical exercise: a systematic review. Rheumatology (Oxford) 2008, 47:239-248.

7. Orzano J, Scott JG: Diagnosis and treatment of obesity in adults: an applied evidence-based review. J Am Board Fam Pract 2004, 17:359-369.

8. Poirier P, Giles TD, Bray GA, Hong Y, Stern JS, Pi-Sunyer FX Eckel RH: Obesity and cardiovascular disease: pathophysiology, evaluation, and effect of weight loss. Arterioscler Thromb Vasc Biol 2006, 26:968-976.

9. Frieden TR, Bloomberg MR: How to prevent $\mathbf{1 0 0}$ million deaths from tobacco. Lancet 2007, 369:1758-1761.

10. Akbartabartoori M, Lean ME, Hankey CR: Relationships between cigarette smoking, body size and body shape. Int J Obes (Lond) 2005, 29:236-243.

11. Eisenberg D, Quinn BC: Estimating the effect of smoking cessation on weight gain: an instrumental variable approach. Health Serv Res 2006, 41:2255-2266.

12. Metsios GS, Stavropoulos-Kalinoglou A, Nevill AM, Douglas KMJ, Koutedakis $Y$, Kitas GD: Smoking significantly increases basal metabolic rate in patients with rheumatoid arthritis. Ann Rheum Dis 2008, 67:70-73.

13. Arnett FC, Edworthy SM, Bloch DA, McShane DJ, Fries JF, Cooper NS, Healey LA, Kaplan SR, Liang MH, Luthra HS, Medsger TA Jr, Mitchell DM, Neustadt DH, Pinals RS, Schaller JG, Sharp JT, Wilder RL, Hunder GG: The American Rheumatism Association 1987 revised criteria for the classification of rheumatoid arthritis. Arthritis Rheum 1988, 31:315-324.

14. Prevoo ML, van 't Hof MA, Kuper HH, van Leeuwen MA, Putte LB van de, van Riel PL: Modified disease activity scores that include twenty-eight-joint counts. Development and validation in a prospective longitudinal study of patients with rheumatoid arthritis. Arthritis Rheum 1995, 38:44-48.

15. Kirwan JR, Reeback JS: Stanford Health Assessment Questionnaire modified to assess disability in British patients with rheumatoid arthritis. Br J Rheumatol 1986, 25:206-209.

16. Obesity: preventing and managing the global epidemic. Report of a WHO Consultation. World Health Organ Tech Rep Ser 2000, 894:1-253.

17. Expert Panel on Detection Evaluation and Treatment of High Blood Cholesterol in Adults: Executive Summary of The Third Report of The National Cholesterol Education Program (NCEP) Expert 
Panel on Detection, Evaluation, And Treatment of High Blood Cholesterol In Adults (Adult Treatment Panel III). JAMA 2001, 285:2486-2497.

18. Schutz Y, Kyle UU, Pichard C: Fat-free mass index and fat mass index percentiles in Caucasians aged 18-98 y. Int J Obes Relat Metab Disord 2002, 26:953-960.

19. Tanaka $\mathrm{K}, \mathrm{Kim} \mathrm{H}$, Nakanishi $\mathrm{T}$, Amagi H: Multifrequency impedance method for the assessment of body composition in Japanese adults. J Exercise Sports Physiol 1999, 6:37-45.

20. Oppliger RA, Nielsen DH, Shetler AC, Crowley ET, Albright JP: Body composition of collegiate football players: bioelectrical impedance and skinfolds compared to hydrostatic weighing. $J$ Orthop Sports Phys Ther 1992, 15:187-192.

21. Gray D, Bray G, Gemayel N, Kaplan K: Effect of obesity on bioelectrical impedance. Am J Clin Nutr 1989, 50:255-260.

22. Bolanowski M, Nilsson BE: Assessment of human body composition using dual-energy $x$-ray absorptiometry and bioelectrical impedance analysis. Med Sci Monit 2001, 7:1029-1033.

23. Demura S, Sato S, Kitabayashi T: Percentage of total body fat as estimated by three automatic bioelectrical impedance analyzers. J Physiol Anthropol Appl Human Sci 2004, 23:93-99.

24. Lofthouse CM, Azad F, Baildam EM, Akobeng AK: Measuring the nutritional status of children with juvenile idiopathic arthritis using the bioelectrical impedance method. Rheumatology (Oxford) 2002, 41:1172-1177.

25. Demura S, Sato S, Kitabayashi T: Estimation accuracy of percent total body fat and percent segmental fat measured by singlefrequency bioelectrical impedance analysis with 8 electrodes: the effect of difference in adiposity. J Sports Med Phys Fitness 2005, 45:68-76.

26. Lemmey A, Maddison P, Breslin A, Cassar P, Hasso N, McCann R, Whellams $\mathrm{E}$, Holly J: Association between insulin-like growth factor status and physical activity levels in rheumatoid arthritis. J Rheumato/ 2001, 28:29-34.

27. Metsios GS, Stavropoulos-Kalinoglou A, Douglas KM, Koutedakis Y, Nevill AM, Panoulas VF, Kita M, Kitas GD: Blockade of tumour necrosis factor-\{alpha\} in rheumatoid arthritis: effects on components of rheumatoid cachexia. Rheumatology (Oxford) 2007, 46:1824-1827.

28. Fendrich M, Mackesy-Amiti ME, Johnson TP, Hubbell A, Wislar JS: Tobacco-reporting validity in an epidemiological drug-use survey. Addict Behav 2005, 30:175-181.

29. Goddard E: General Household Survey 2005: Smoking and drinking among adults, 2005 London, UK: Office for National Statistics; 2006.

30. Saag KG, Cerhan JR, Kolluri S, Ohashi K, Hunninghake GW, Schwartz DA: Cigarette smoking and rheumatoid arthritis severity. Ann Rheum Dis 1997, 56:463-469.

31. Albanes D, Jones DY, Micozzi MS, Mattson ME: Associations between smoking and body weight in the US population: analysis of NHANES II. Am J Public Health 1987, 77:439-444.

32. Nicklas BJ, Tomoyasu N, Muir J, Goldberg AP: Effects of cigarette smoking and its cessation on body weight and plasma leptin levels. Metabolism 1999, 48:804-808.

33. Klok MD, Jakobsdottir S, Drent ML: The role of leptin and ghrelin in the regulation of food intake and body weight in humans: a review. Obes Rev 2007, 8:21-34.

34. Chen H, Hansen MJ, Jones JE, Vlahos R, Bozinovski S, Anderson GP, Morris MJ: Cigarette smoke exposure reprograms the hypothalamic neuropeptide $\mathrm{Y}$ axis to promote weight loss. Am $J$ Respir Crit Care Med 2006, 173:1248-1254.

35. Billington CJ, Briggs JE, Grace M, Levine AS: Effects of intracerebroventricular injection of neuropeptide $Y$ on energy metabolism. Am J Physiol. 1991, 260:R321-327.

36. Collins LC, Cornelius MF, Vogel RL, Walker JF, Stamford BA: Effect of caffeine and/or cigarette smoking on resting energy expenditure. Int J Obes Relat Metab Disord 1994, 18:551-556.

37. Collins LC, Walker J, Stamford BA: Smoking multiple high- versus low-nicotine cigarettes: impact on resting energy expenditure. Metabolism 1996, 45:923-926.

38. Perkins K, Epstein L, Marks B, Stiller R, Jacob R: The effect of nicotine on energy expenditure during light physical activity. $N$ Engl J Med 1989, 320:898-903.

39. Perkins KA: Metabolic effects of cigarette smoking. J App/ Physiol 1992, 72:401-409.

40. Walker JF, Collins LC, Rowell PP, Goldsmith $\sqcup$, Moffatt RJ, Stamford BA: The effect of smoking on energy expenditure and plasma catecholamine and nicotine levels during light physical activity. Nicotine Tob Res 1999, 1:365-370.

41. Dallosso HM, James WP: The role of smoking in the regulation of energy balance. Int $J$ Obes 1984, 8:365-375.

42. Chajek-Shaul T, Berry EM, Ziv E, Friedman G, Stein O, Scherer G, Stein Y: Smoking depresses adipose lipoprotein lipase response to oral glucose. Eur J Clin Invest 1990, 20:299-304.

43. Sztalryd C, Hamilton J, Horwitz BA, Johnson P, Kraemer FB: Alterations of lipolysis and lipoprotein lipase in chronically nicotine-treated rats. Am J Physiol. 1996, 270:E215-223.

44. Ferrara CM, Kumar M, Nicklas B, McCrone S, Goldberg AP: Weight gain and adipose tissue metabolism after smoking cessation in women. Int J Obes Relat Metab Disord 2001, 25:1322-1326.

45. Canoy D, Wareham N, Luben R, Welch A, Bingham S, Day N Khaw KT: Cigarette smoking and fat distribution in 21,828 British men and women: a population-based study. Obes Res 2005, 13:1466-1475

46. Petersen AM, Magkos F, Atherton P, Selby A, Smith K, Rennie MJ, Pedersen BK, Mittendorfer B: Smoking impairs muscle protein synthesis and increases the expression of myostatin and MAFbx in muscle. Am J Physiol Endocrinol Metab 2007, 293:E843-848.

47. Boyle P, Autier P, Bartelink H, Baselga J, Boffetta P, Burn J, Burns HJ, Christensen L, Denis L, Dicato M, Diehl V, Doll R, Franceschi S, Gillis CR, Gray N, Griciute L, Hackshaw A, Kasler M, Kogevinas M, Kvinnsland S, La Vecchia C, Levi F, McVie JG, Maisonneuve P, Martin-Moreno JM, Bishop JN, Oleari F, Perrin P, Quinn M, Richards $\mathrm{M}$, et al:: European Code Against Cancer and scientific justification: third version (2003). Ann Oncol 2003, 14:973-1005.

48. Grundy SM, Brewer HB Jr, Cleeman Jl, Smith SC Jr, Lenfant C American Heart Association; National Heart, Lung, and Blood Institute: Definition of metabolic syndrome: Report of the National Heart, Lung, and Blood Institute/American Heart Association conference on scientific issues related to definition. Circulation 2004, 109:433-438. 